\title{
Migrations of the North Atlantic Polar Front during the last 300 ka: evidence from planktic foraminiferal data
}

Leyla Bashirova (1,2), Evgenia Kandiano (3), Vadim Sivkov (1,2), and Henning Bauch (4)

(1) Atlantic Branch of the P.P. Shirshov Institute of Oceanology of Russian Academy of Sciences, Kaliningrad, Russian Federation (bas_leila@mail.ru, sivkov@kaliningrad.ru), (2) Immanuel Kant Baltic Federal University, Kaliningrad, Russian Federation (bas_leila@mail.ru, sivkov@kaliningrad.ru), (3) GEOMAR, Kiel, Germany (ekandiano@geomar.de), (4) Mainz Academy of Sciences, Humanities, and Literature, Germany, GEOMAR, Kiel, Germany (hbauch@geomar.de)

Polar front (PF) migrations were reconstructed for middle latitudes of the North Atlantic during the last 300000 using planktic foraminiferal census data and derived from them sea surface temperature (SST) estimates in two sediment cores, AMK-4438 and M23414. Currently both investigated sites underlie the North Atlantic Current (NAC). Faunal results were supported by stable isotopic and IRD data. It was found that the arctic waters had propagated to the study area only during glacial winter seasons of MIS 2, 6, and 8 . The northern part of the study area was influenced by the arctic waters more often than its southern part. During MIS 8 and 6 isotherms in the study area had mainly the subzonal orientation, while during MIS 2-4 they had the submeridional orientation. In general, during the investigated interglaciations, PF was located northward and westward from the study area, which was influenced by NAC. However, during MIS 7, PF was situated closer to the study area, in comparison with its modern position. During MIS 7 and 1, the subzonal orientation of the isotherms prevailed. For the MIS 5e period, we observed the most distant retreat of PF from the investigated area, which is in accordance with previous investigations reporting an anomalous deflection of NAC to the north-west. 